\title{
Experimental Methods of Determining Fracture Toughness of Fiber Reinforced Polymer Composites under Various Loading Conditions
}

\author{
M.S. Sham Prasad ${ }^{* 1}$, C.S. Venkatesha², T. Jayaraju ${ }^{3}$ \\ ${ }^{1}$ Dept. of Industrial \& Production Engineering, National Institute of Engineering, Mysore, India \\ ${ }^{2}$ Dept. of Mechanical Engineering, U BDT college of Engineering, Davangere, India \\ ${ }^{3}$ Dept. of Mechanical Engineering, National Institute of Engineering, Mysore, India \\ *Corresponding Author:-
}

\begin{abstract}
Polymer composites is a typical material consisting of a matrix reinforced with fiber/filler and the general nature of construction of the material itself provides innumerable sites for the initiation of a defect or for the growth of delamination. The life expectancy of composite structure requires a clear understanding of the material's response to the growth of interlaminar delamination under Mode I, Mode II, Mode III and Mixed Modes. Fracture testing of fiber reinforced polymer-matrix composites is an active area of research. Even though substantial progress in the area of fracture testing has been achieved, there are still several problems awaiting solution. The new aspects in the experimental studies of interlaminar and intralaminar fracture toughness of polymer matrix composites were emphasized in this review paper. The different modes to evaluate the fracture energy were listed and their suitability was mentioned.
\end{abstract}

Keywords: Interlaminar, Delamination, Intralaminar, Fracture toughness

\section{INTRODUCTION}

Composites belong to a new class of materials developed that are strong, have low densities, and not easily corroded. Polymer matrix composites can be processed to get higher mechanical strength and other desired properties. Composite materials are heterogeneous in composition and an-isotropic in mechanical behavior. Polymer composites have emerged as important structural engineering materials in automotive, marine, aerospace, transportation, infrastructure applications and as well as in civil engineering applications, because of their high strength to weight ratio. Compared to metals, fracture toughness characterization of composite materials are still in the process of development. The aim of the review paper is to present and discuss problems from the development of the test methods arising mainly from the specific properties of Polymer Matrix Composites. 


\section{FRACTURE MECHANICS}

Tensile test results apply to material that does not contain cracks or stress concentrators, such as brittle inclusions. When crack like defects are present either as surface cracks or internal ones, failure may begin at much lower applied stresses. The applied stress is greatly magnified at the crack tip due to zero area (theoretically). For a ductile material, it can deform locally when the stress is high, blunting the crack tip reducing the intensity of stress [1]. For brittle material, the crack will propagate through the stressed region with little deformation. The small scale plastic region around the crack will continue to propagate across the specimen. Fracture may be defined as the mechanical separation of a solid owing to the application of stress. Fractures of engineering material are categorized as ductile or brittle fractures. Ductile fractures absorb more energy, while brittle fractures absorb little energy, and are generally characterized by fracture with flat surfaces. Fracture toughness is related to the amount of energy required to create fracture surfaces. In brittle materials such as glass the energy required for fracture is simply the intrinsic surface energy of the material, as demonstrated by Griffith. For structural alloys at room temperature considerably energy is required for fracture because plastic deformation accompanies the fracture process. The application of fracture mechanics concepts has identified and quantified the primary parameters that affect structural integrity. These parameters include the magnitude and range of the applied stresses, the size, shape, orientation of cracks / crack like defects, rate of propagation of the existing cracks and the fracture toughness of the material. Two categories of fracture mechanics are Linear Elastic Fracture Mechanics (LEFM) and ElasticPlastic Fracture Mechanics (EPFM). The Linear Elastic Fracture Mechanics (LEFM) approach to fracture analysis assumes that the material behaves elastically at regions away from the crack, except for a small region of inelastic deformation at the crack tip. The fracture resistance is determined in terms of the stress- intensification factor, $\mathrm{K}$ and strain energy release rate $\mathrm{G}$. The energy released during rapid crack propagation is a basic material property and is not influenced by part size. According to ASTM the stress intensity factor K can be written as

$$
K_{I}=\sigma \sqrt{\pi a f(g)}
$$

Where ' $a$ ' is the initial crack length, ' $f(g)$ ' is the dimensionless factor for the specimen geometry and loading condition and the $\mathrm{K}_{\mathrm{I}}$, the Mode I critical stress intensity factor. The specimen size must be chosen such that there is small scale plasticity around the crack tip. If a large plastic zone develops ahead of the crack tip then the condition of "small scale yielding" for LEFM applicability are not met [2]. One of the underlying principles of fracture mechanics is that the unstable fracture occurs when the stress intensity factor at the crack tip reaches a critical value, $\mathrm{K}_{\mathrm{C}}$. The greater the value of fracture toughness, the higher the intensity of stress required to produce crack propagation and the greater the resistance of the material to brittle fracture. The critical stress intensity factor is determined using relatively simple laboratory specimen, the limiting value being $\mathrm{K}_{\mathrm{IC}} / \mathrm{K}_{\mathrm{IIC}} / \mathrm{K}_{\mathrm{IIIC}}$. The Elastic-Plastic fracture mechanics is used when there is large scale crack tip plasticity (blunting).

\subsection{Modes of Fracture}

Figure 1 defines the three modes of loading, Mode I, opening or tensile mode, Mode II, sliding or shear mode, and Mode III, tearing mode. Fracture mechanics concepts are essentially the same 
for each mode. However the great majority of all actual cracking and fractures cases in metals are mode I problems. A crack in the very early stage of development will turn into a direction in which it experiences only Mode I loading, unless it is prevented from doing so by geometrical confinement. For this reason fracture mechanics of metal is generally confined to Mode I.

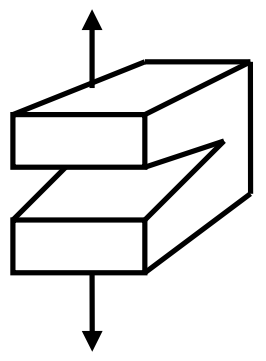

Tensile

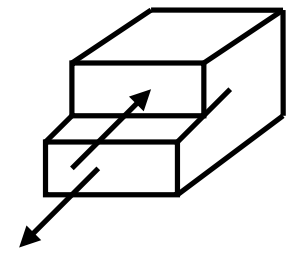

Sliding shear

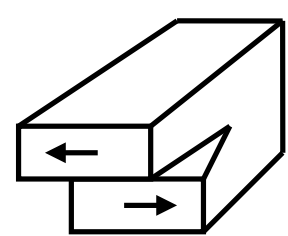

Tearing shear

Figure 1. Crack Opening Modes

\subsection{Fracture of Polymer Composites}

Fracture can also be studied in polymers, glass and ceramics which are brittle materials. Polymer composite materials often show a mixture of ductile and brittle failure processes. There are several fracture modes in polymer composites such as delamination or interlaminar fracture, matrix cracking or intralaminar fracture, matrix-fiber debonding, fiber breaking, fiber pullout etc [3]. In the fiber reinforced polymer composite, the matrix absorbs energy in tearing while the high strength fibers break by brittle cleavage [4]. The surface of fibers pulled out from the matrix can also be seen. The factors that contribute to the fiber reinforced composites toughness are: debonding between matrix and fibers, the cracks deflection due to tilting or twisting movement around the fiber. The fibers pullout of the matrix by the pull out mechanism and dissipate energy by friction. The pulled fibers may bridge both the crack surfaces, absorbing the applied stress and delay the crack growth.

\subsection{Interlaminar (Delamination) Fracture Toughness}

Interlaminar fracture is one of the major problems for fiber reinforced polymer composites. Its occurrence greatly reduces the stiffness of a structure, leading to failure during service [5]. The structural performance of laminated composites is seriously affected by delaminations. The interlaminar performance is characterized by weakness under both tensile and shear stresses. Such interlaminar stresses become significant and affect the overall performance where geometrical and material discontinuities exist. Delamination and their growth are characterized by strain energy release rate $(\mathrm{G})$, and the manner in which the load is applied. A delamination may be loaded in Mode I (tensile), Mode II (shear), Mode III (tearing shear), or it may be loaded in combination of these Modes. The critical strain energy release rate (Gc) at which the delamination actually begins to extend vary significantly depending on the mode of loading [6]. Characterization of delamination resistance has thus been the subject of researchers, which led to the development of various test methods. ASTM is working on standards to measure Gc under a variety of loading conditions. The ASTM standard, ASTM D 5528 recommends the use of 
Double Cantilever Beam (DCB) test to measure the Mode I fracture toughness $\mathrm{G}_{\mathrm{IC}}$ of fiber reinforced polymer composites. The End Notch Flexure (ENF) test for pure Mode II fracture toughness G $_{\text {IIC }}$ common among researchers is yet to be approved by ASTM. For pure Mode III fracture toughness $\mathrm{G}_{\text {IIIC }}$, Ratcliffe J [7], suggested the use of the Edge Crack Torsion Test (ECT) which the ASTM is working to standardize. ASTM D6671 recommends the use of Mixed-Mode bending (MMB) test that can measure fracture toughness over a wide range of combinations of Mode I and Mode II loading.

\subsubsection{Mode I Interlaminar fracture toughness testing}

The preferred specimen type in most Mode I interlaminar fracture test is double cantilever beam (DCB), which consists of a rectangular uniform thickness unidirectional laminated composite specimen schematically shown in Figure 2. A non-adhesive Teflon film was inserted in the midplane of the laminate during fabrication which acted as delamination initiator. The loading

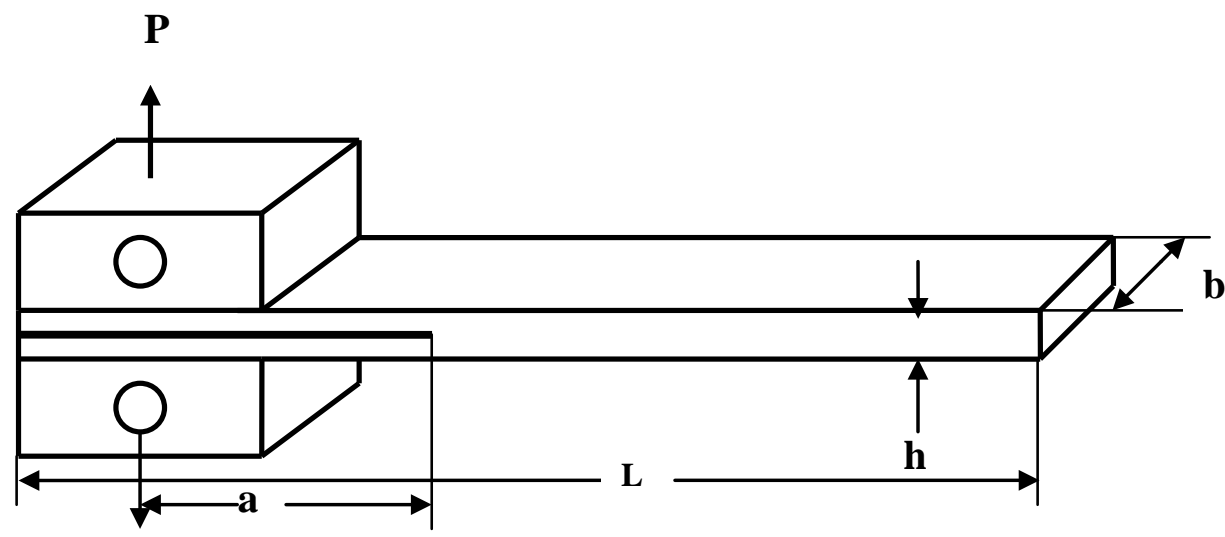

Figure 2. Double cantilever beam specimen with load blocks used for Mode I testing

blocks were mounted on the top and bottom surfaces of the end of DCB specimen arms. The delaminated end of the DCB specimen was opened by quasi-static loading at a displacement control mode with a constant crosshead speed of $1-5 \mathrm{~mm} / \mathrm{min}$. Delamination lengths are determined visually during the test. For more accurate delamination length readings the use of a travelling microscope is recommended by ASTM.

\subsubsection{Interlaminar fracture toughness, GIC calculations [8]:}

The interlaminar fracture toughness calculation is based on beam theory (with corrections for load-blocks) or on experimental compliance calibration or a modified compliance calibration as described by ASTM D5528 [8]. The $G_{\text {IC }}$ values determined by these three methods differed by not more than $3.1 \%$, none of the them were superior to the others. However, MBT method is recommended as it has yield the most repeated values of $G_{\text {IC }}$ for $80 \%$ of specimen tested during ASTM round robin testing[8,9]. The area method is not recommended because it will not yield an initiation value of $G_{\text {IC }}$ or a delamination resistance curve. 


\subsubsection{Modified beam theory (MBT) method:}

The strain energy release rate is calculated as follows:

$$
G_{I}=\frac{3 P \delta}{2 b a}
$$

Where $\mathrm{P}=$ load, $\delta=$ load point displacement, $\mathrm{b}=$ specimen width and $\mathrm{a}=$ delamination length In practice, equation (2) will overestimate $G_{I}$ because the beam is not perfectly built-in (i.e., rotation may occur at the delamination front). The modified equation (3) corrects for this rotation by treating the DCB as if it contained a slightly longer delamination, a $+\Delta$ where $\Delta$ may be determined experimentally by generating a least squares plot of the cube root of compliance, $C^{1 / 3}$ as a function of delamination length.

$$
G_{I}=\frac{3 P \delta}{2 b(a+\Delta)}
$$

\subsubsection{Compliance calibration (CC) method:}

In this method a least squares graph of $\log (\delta i / \mathrm{Pi})$ versus $\log (\mathrm{a})$ is generated using the visually observed delamination onset values and all the propagation values. A straight line is drawn through the data that results in the best least-squares fit. The exponent $n$ from the slope of this line is calculated according to $n=\Delta x / \Delta y$ where $\Delta_{\mathrm{y}} \& \Delta x$ are increment value of $\mathrm{y} \& \mathrm{x}$ respectively. The Mode I interlaminar fracture toughness is determined as follows:

$$
G_{I}=\frac{n P \delta}{2 b a}
$$

\subsubsection{Modified compliance calibration (MCC) method:}

In this method a least squares graph of the delamination length normalized by specimen thickness, $a / h$, as a function of the cube root of compliance, $C^{1 / 3}$ is plotted using the visually observed delamination onset values and all the propagation values. The slope of this line is $S_{1}$. The Mode I interlaminar fracture toughness is calculated as follows:

$$
G_{I}=\frac{3 P^{2} C^{2 / 3}}{2 S_{1} b h}
$$

Morais et al. [10-11] and Choi et al. [12] assessed the applicability of DCB test for multidirectional laminates. Multidirectional laminates frequently pose problems because of crack branching or deviations of the delamination from the central plane. Both effects invalidate the analysis according to the ASTM standard D5528. Delamination resistance on multidirectional laminates can probably be quantified for initiation only. No significant dependence on the delaminating interface (fiber orientation) was observed. For cross-ply composites (alternating $0^{0}$ and $90^{\circ}$ orientations stacked on top of each other), extensive testing yielded about $50 \%$ of 
invalid tests due to deviation from the mid-plane[13,14]. These laminates yielded initiation values similar to those observed in the corresponding unidirectional laminate.

\subsubsection{Mode II interlaminar fracture toughness testing}

Most high performance composites are designed [15] to have superior in-plane strength and stiffness. Interlaminar performance is characterized by pronounced weakness under both shear and tensile stresses. In many laminates, the strength reduction has been observed due to delamination between plies. Delamination induced failure is normally a result of a combination of compressive and bending stresses caused by the delaminated plies as they buckle out of plane. Fiber breakage and matrix cracking also have an effect on the strength. Interlaminar shear, tension and the matrix cracking largely cause internal delamination which in turn gives rise to residual stresses that further reduces the strength [16].

The End-notched flexure (ENF) test [17] is one of the methods designed to measure the interlaminar fracture toughness under in-plane shear deformation mode, commonly known as Mode II. Early round robin work on mode II ENF had been conducted jointly by JIS, ASTM and ESIS but has not resulted in international consensus [13]. Several factors contributed to that, first the ENF-test is essentially unstable and thus allows only determination of initiation values but not of resistance curves. Second, the question of friction contributions was raised and this resulted in the question whether Mode II data were to be regarded as apparent values with no significance as materials data [18]. The measured $\mathrm{G}_{\text {IIC }}$ is believed to represent the critical strain energy release rate for crack growth from the insertion film. In this test, the load was introduced by flexural forces to produce a crack from the insert. The crack then extended as a result of shear forces at the crack tip as shown in Figure 3.

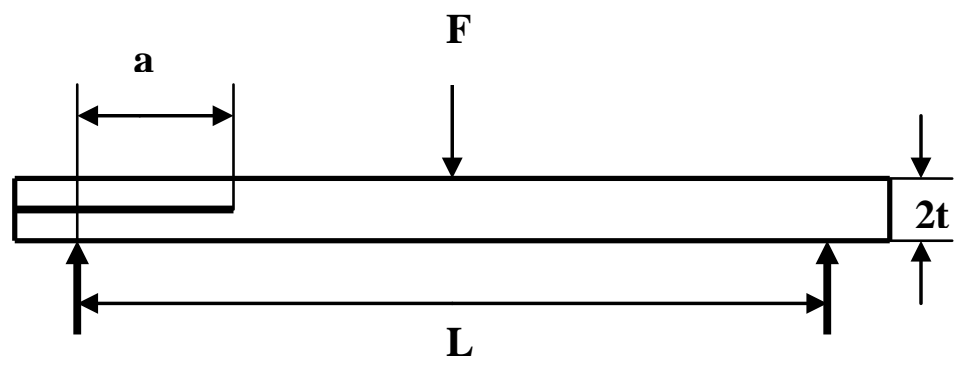

Figure 3. ENF specimen under load

Mode II interlaminar fracture toughness is calculated from the initial crack length and the loaddeflection curve using the highest load and deflection level [19] as

$$
G_{I I}=\frac{9 F \delta a^{2}}{2 B\left(1 / 4 L^{3}+3 a^{3}\right)}
$$

Where $\mathbf{F}$ is the load (N), $\boldsymbol{\delta}$ the displacement (mm), B the specimen width (mm) and a $\square$ is Łe delamination length (mm). 


\subsubsection{Mode III interlaminar fracture toughness testing}

Extensive work on Mode I and Mode II fracture is reported in the literature, but less work has been reported on Mode III despite its importance in edge delamination [20,21]. Donaldson [22] has reported that split cantilever beam (SCB) tests can be used to measure the Mode III fracture energy $\mathrm{G}_{\text {IIIC. }}$. The finite element (FE) analyses conducted by Martin [23] showed the presence of a significant Mode II component. The crack rail shear (CRS) test conducted by Becht and Gillespie [24] has yielded the same problem. Recent studies have focused on the edge crack torsion (ECT) test, which the ASTM is working to standardize.

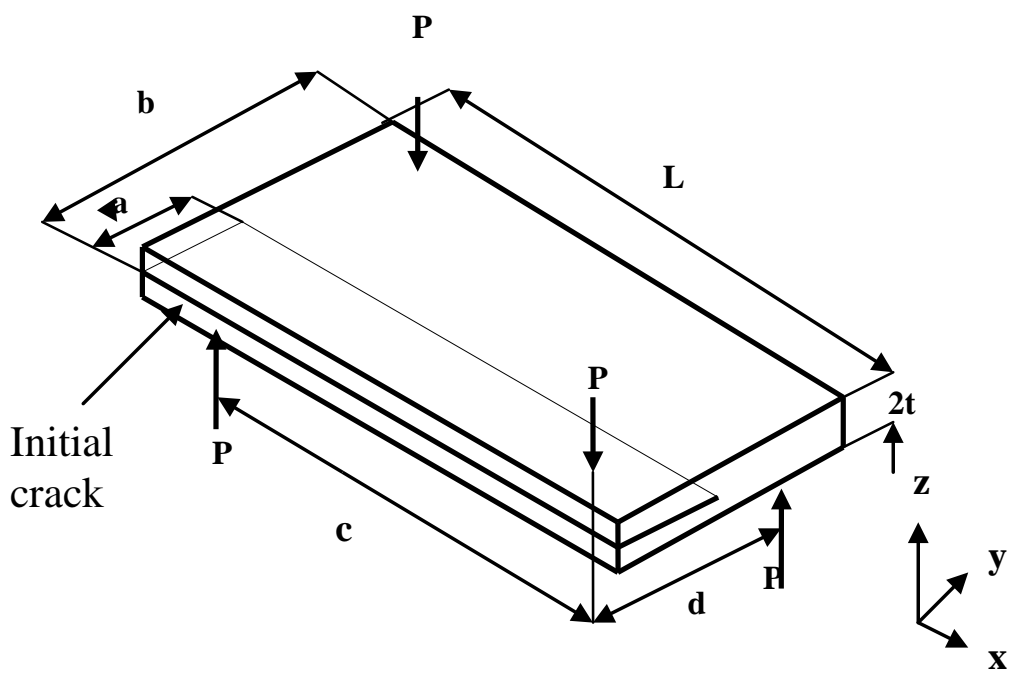

Figure 4. The ECT specimen

The ECT specimen shown in Figure 4 consisted of three support pins and an upper loading pin, which generate torsion moments responsible for the Mode III shear sliding. Lee [25] proposed specimen stacking sequence $\left[90^{0} /\left( \pm 45^{0}\right) \mathrm{n} /\left(-45^{0}\right) \mathrm{n} / 90^{0}\right] \mathrm{s}$ with $\mathrm{n}=3$ or 4 , so that the delamination propagates at mid-thickness between $90^{0}$ plies. However, $\pm 45^{0}$ plies are needed for torsional stiffness and strength. Numerical analysis [24] of the ECT specimen showed some Mode II component near the edges. The results of ASTM D30 round robin [13] organized in the year 1997 to evaluate this test on carbon/epoxy samples indicated large scatter and considerable non-linearity. The compliance is defined as $\mathrm{C}=\delta / \mathrm{F}$ with $\mathrm{F}=2 \mathrm{P}$, i.e. the loading was applied to both upper pins as shown in Figure 4.

The Mode III fracture toughness is calculated by Irwin-Kies relation[7,20] as

$$
G_{I I I}=\frac{m F^{2}}{2 c(A-m a)^{2}}
$$

Where $A=\frac{32 \mu_{x y, 0} h^{3} b}{3 c d^{2}}, \quad m=\frac{32 \mu_{x y, 0} h^{3}}{3 c d^{2}}\left(1-\frac{\mu_{x y, 1}}{4 \mu_{x y, 0}}\right) \quad$ and $\mu_{x y, 0} \quad$ and $\mu_{x y, 1}$ designate the 
CLT torsional shear moduli of the uncracked and cracked parts of the specimen, respectively, derived by Lee [25].

\subsubsection{Mixed mode I+II interlaminar fracture toughness testing}

The problem of delamination in composite materials has made significant developments in interlaminar fracture testing with different modes. Early studies were concentrated on pure Mode I and pure Mode II fracture of unidirectional laminates, but in recent years the attention has diverted on realistic Mixed Mode I + II loadings [26]. However, a few literatures are available on Mixed Mode fracture of multidirectional and woven laminates [26-29,]. The mixed mode bending (MMB) test is considered the best method for evaluating the fracture toughness over a wide range of Mode combinations as recommended by ASTM D 6671[30].

The MMB test shown in Figure 5 can be viewed as the superposition of the double cantilever beam and end notched flexure tests. Force equilibrium of the loading lever enables determination of the pure mode loads as suggested by ASTM D6671/ D6671M.

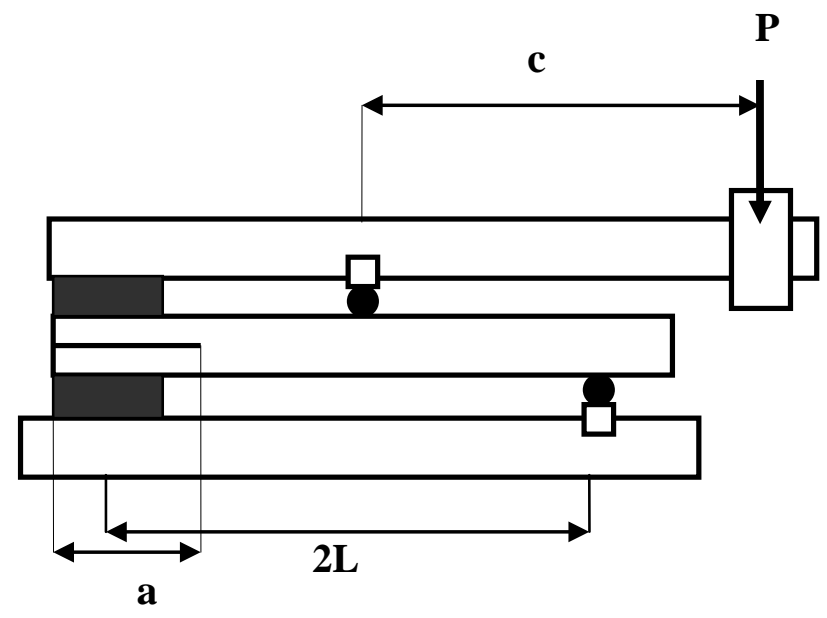

Figure 5. Mixed Mode Bending specimen

$$
\begin{gathered}
G_{I}=\frac{12 F^{2}(3 c-L)^{2}}{16 b^{2} h^{3} L^{2} E_{I f}}(a+\chi h)^{2} \\
G_{I I}=\frac{9 F^{2}(c+L)^{2}}{16 b^{2} h^{3} L^{2} E_{I f}}(a+0.42 \chi h)^{2} \\
G_{T}=G_{I}+G_{I I}
\end{gathered}
$$

\subsection{Intralaminar Fracture Toughness}

The matrix cracking or a crack apparently running parallel to fibers (Intralaminar) through the thickness is also one of the problems encountered in fiber reinforced polymer composite. Extensive research work carried on interlaminar fracture has led to the development and standardization of interlaminar fracture toughness testing on various Modes. In recent years 
attention has been diverted to evaluation of intralaminar fracture. Since a standard test method has not been evolved, the plane strain fracture toughness test methods based on ASTM D 5045 (meant for plastics /particulate polymer composite) is used by researchers.

Garg [31] studied the influence of width, thickness and specimen type on intralaminar (transverse) fracture of graphite/ epoxy laminates using compact- tension and three- point bend specimens. His result shows that that $\mathrm{K}_{\mathrm{IC}}$ is independent of geometry and thickness of the specimen. Parhizgar et.al. [32] showed that intralaminar fracture toughness depends on fiber orientation, the value of $\mathrm{K}_{\mathrm{IC}}$ being twice for $90^{\circ}$ oriented fibers then $0^{0}$ oriented fibers, even though the failure is due to matrix cracking. Jose et. al. [33] investigated intralaminar fracture toughness on carbon / epoxy with $0^{0}, 90^{\circ}$ fiber oriented and cross-ply $\left(0^{0} / 90^{\circ}\right)$ laminates. They observed that the mode of failure is by self similar crack breaking the fiber for cross ply laminate. For $0^{0}$ and $90^{\circ}$ fiber oriented laminates the mode of failure was similar to results of Parhizgar. Pinho et. al [34,35] have found that the Mode I intralaminar critical energy release rate for through the thickness crack growth was very similar to the interlaminar toughness in unidirectional laminates, so interlaminar critical energy release rate can be a good approximation for intralaminar energy release rate.

\subsubsection{Intralaminar fracture toughness testing}

These test methods based on ASTM D 5045 involve loading a notched specimen that has been precracked, in either tension (compact tension) or three-point bending [36]. The significance of test methods and many conditions of testing are identical to ASTM E 399. The specimens for fracture toughness testing is either Compact Tension or Three Point Bend was machined from the laminates in accordance with the dimension given ay ASTM D 5045 as shown in Figure 6 and Figure 7 respectively.

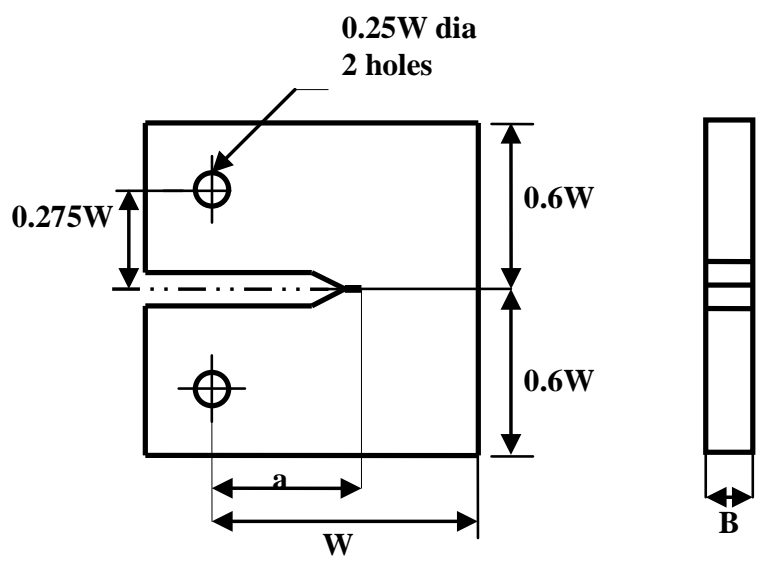

Figure 6. Compact Tension specimen configuration

The initial portion a $\mathrm{V}$ notch has to be machined with a milling cutter or with a diamond saw and a starter crack has to be introduced at the root of the notch by tapping or sawing a fine razor blade [36]. The ratio of crack length to width (a / W) is to be maintained between 0.45 and 0.55 . The pre-cracked fracture specimen is loaded with suitable loading devices. For Compact tension specimen a loading clevis is required and for loading three point bend specimens a bending rig 
with either moving or stationary rollers of sufficiently large diameter is required. The test is performed under displacement control mode with displacement rates of $0.5 \mathrm{~mm} / \mathrm{min}$ or $1 \mathrm{~mm} /$ min [34] and the load versus displacement curve is obtained. It is recommended [36] that at least three test specimens need to be tested for each material. The $K_{I C}$ value is calculated from this load by equations that have been established on the basis of LEFM.

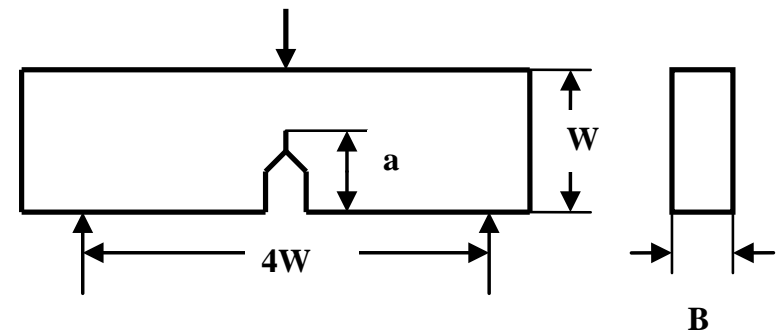

Figure 7. Three Point Bend (SENB) specimen configuration

\subsubsection{Calculation of critical stress intensity factor, $K_{I C}[36]$ :}

In order to establish that a valid $\mathrm{K}_{\mathrm{IC}}$ has been determined, calculate a conditional result, $\mathrm{K}_{\mathrm{Q}}$. Load the specimen and obtain Load -displacement curve. Draw a best straight line to determine the initial compliance, $C$. $C$ is given by the reciprocal of the slope of line $(C=\tan \theta)$. Draw a second line with compliance $5 \%$ greater than that of initial line. If the maximum load that the specimen was able to sustain, $\mathrm{P}_{\max }$, falls within the two lines, use $\mathrm{P}_{\max }$ to calculate $\mathrm{K}_{\mathrm{Q}}$. If $\mathrm{P}_{\max }$ falls outside the lines then use the intersection of second line and the load curve as $\mathrm{P}_{\mathrm{Q}}$. Furthermore, if $\mathrm{P}_{\max } / \mathrm{P}_{\mathrm{Q}}<1.1$, then use $\mathrm{P}_{\mathrm{Q}}$ in the calculation of $\mathrm{K}_{\mathrm{Q}}$. However, if $\mathrm{P}_{\max } / \mathrm{P}_{\mathrm{Q}}>1.1$, the test is invalid. Check the validity of $\mathrm{K}_{\mathrm{Q}}$ via the size criteria. Calculate $2.5\left(K_{Q} / \sigma_{y}\right)^{2}$, where $\sigma_{\mathrm{y}}$ is the yield stress of the material. If this value is less than the specimen thickness, $\mathrm{B}$, the crack length, $a$, and the ligament $\left(\mathrm{W}-\mathrm{a}\right.$ ), then $\mathrm{K}_{\mathrm{Q}}$ is equal to $\mathrm{K}_{\mathrm{IC}}$. Otherwise the test is not a valid $\mathrm{K}_{\mathrm{IC}}$ test.

\subsubsection{For compact tension specimen:}

The fracture loads $\mathrm{P}_{\mathrm{Q}}$, obtained from the tests are used to determine $\mathrm{K}_{\mathrm{IC}}$ values $\left(\mathrm{MPa} \cdot \mathrm{m}^{1 / 2}\right.$ ) as a measure of fracture toughness by using the following data reduction scheme.

$$
K_{I C}=\left(\frac{P_{Q}}{B W^{1 / 2}}\right) f(x)
$$

Where $\mathrm{B}=$ specimen thickness, $\mathrm{cm}, \mathrm{W}=$ specimen width $, \mathrm{cm}, \mathrm{a}=$ crack length, $\mathrm{cm} \quad$ and

$$
\text { Where } f(x)=\frac{(2+x)\left(0.866+4.64 x-13.32 x^{2}+14.72 x^{3}-5.64 x^{4}\right)}{1-x^{3 / 2}}
$$

\subsubsection{Three point bend specimen (SENB):}

The fracture loads $\mathrm{P}_{\mathrm{Q}}$, obtained from the tests are similarly used to determine $\mathrm{K}_{\mathrm{IC}}$ values $\left(\mathrm{MPa} . \mathrm{m}^{1 / 2}\right)$ as a measure of fracture toughness by using the following data reduction scheme 


$$
\begin{gathered}
K_{I C}=\left(\frac{P_{Q}}{B W^{1 / 2}}\right) f(x) \\
\text { Where } f(x)=6 x^{1 / 2} \frac{\left(1.99-x(1-x)\left(2.15-3.93 x+2.7 x^{2}\right)\right)}{(1+2 x)\left(1-x^{3 / 2}\right)}
\end{gathered}
$$

\section{CONCLUSION}

The development of interlaminar fracture tests of polymer-matrix composites has been rather slow. Even for Mode I loading, standardization of test methods took about a decade. Multidirectional lay-ups frequently pose problems with Mode I loading because of crack branching and/or deviations of the delamination from the central plane. Both effects invalidate the analysis according to the ASTM standard. Tests for other loading Modes and rates are still under development. Early round robin work on Mode II ENF conducted jointly by JIS, ASTM and ESIS has not yet resulted in international consensus. Compared to Mode I and Mode II fracture, much less work has been reported on Mode III, despite its importance in edge delamination. Application of standardized test methods to new types of reinforcements has been tried in research laboratories, but has lead to questions about the validity of the data. Intralaminar fracture toughness testing has recently gained its importance by researchers but still a standard test method has not yet evolved.

\section{REFERENCES}

1. John M Barsom, Stanley, T Rolfe. (1987). Fracture and Fatigue control in structures: Application of Fracture Mechanics. Second Edition. Prentice Hall. Inc. USA.

2. Todd M Mower, Victor C Li. (1987). Fracture characterization of random short fiber reinforced thermoset resin composites. Engineering fracture Mechanics. 26(4): 593-603.

3. C K H Dharan. (1978). Fracture mechanics of composite materials. Journal of engineering materials and technology. 100: 223-247.

4. R V Silva, D Spinelli, W W Bose Filho, S Claro Neto, G O Chierice, J R Tarpani. (2006). Fracture toughness of natural fibers/castor oil polyurethane composites. Composite Science and Technology. 66: 1328-1335.

5. Mehdi Barikani, Hossein Saidpour, and Mutlu Sezen. (2002). Mode-I Interlaminar Fracture Toughness in Unidirectional Carbon-fiber/Epoxy Composites. Iranian Polymer Journal.11(6): 413-423.

6. Reeder J R. (1993). A Bilinear Failure Criterion for Mixed-Mode Delamination. composite Materials: Testing and Design, ASTM STP 1206, E.T.Camponeschi, Jr., Ed.ASTM Int., W. Conshohocken, PA. 11: 303-322.

7. Ratcliffe J. (2004)."Characterization of the Edge Crack Torsion (ECT) Test for Mode III Fracture Toughness Measurement of Laminated Composites", in proceeding of the $19^{\text {th }}$ ASC/ASTM Technical Conference. Atlanta.

8. ASTM D5528. (1994). Standard test method for Mode I interlaminar fracture toughness of unidirectional fiber reinforced polymer matrix composites. 
9. O’Brien T K, and Martin R H. (1993). Results of ASTM Round Robin Testing for Mode I Interlaminar Fracture Toughness of Composite Materials. Journal of Composites Technology and Research. 15(4): 269 - 281.

10. A B de Morais. (2003). Double cantilever beam testing of multidirectional laminates. Composite Part A: Applied Science. A34(12): 1135-1142.

11. Pereira A B, de Morais A B. (2004). Mode I interlaminar fracture of carbon/epoxy multidirectional laminates. Composite Science and Technology. 64: 2261-2270.

12. Choi N S, Kinloch A J, Willams J G. (1999). Delamination fracture of multidirectional carbon-fiber / epoxy composites under mode I, mode II and mixed mode I/II loading. Journal of Composite Material. 33(1): 73-100.

13. A J Brunner, B R K Blackman and P Davies. (2008). A status report on delamination resistance testing of polymer-matrix composites. Engineering Fracture Mechanics.75: 2779-2794.

14. Brunner A J, Flueler P. (2005). Prospects in fracture of engineering laminates. Engineering Fracture Mechanics. 72(6): 899-908.

15. Hossein Saidpour, Mehdi Barikani, and Mutlu Sezen. (2003). Mode-II Interlaminar Fracture Toughness of Carbon/Epoxy Laminates. Iranian Polymer Journal.12 (5): 389-400.

16. Jones R, Broughton W, Mousley R F, and Potter R T. (1985). Compression failure of damaged graphite epoxy laminates. Composite Structures. 3: 167-186.

17. Davies P. (1993). ESIS protocols for interlaminar fracture testing of composites. France, IFREMER brochure.

18. O’Brien T K. (1998). Interlaminar fracture toughness: the long and winding road to standardization. Composites- Part B: Engineering. 29B(1): 57-62.

19. Gibson R F. (1994). Principles of Composite Material Mechanics. McGraw Hill, USA: 395397.

20. A B de Morais, A B Pereira, M F S F de Moura, A G Magalhães. (2009). Mode III interlaminar fracture of carbon/epoxy laminates using the edge crack torsion (ECT) test. Composites Science and Technology. 69: 670-676.

21. Wang S S. (1983). Fracture mechanics for delamination problems in composite materials. Journal of Composite Materials. 17: 210-233.

22. Donaldson S L. (1988). Mode III interlaminar fracture characterization of composite materials. Composite Science and Technology. 32: 225-249.

23. Martin R H. (1991). Evaluation of the split cantilever beam for Mode III interlaminar delamination testing. In: O’Brien TK, editor. ASTM STP 1110. Composite materials: fatigue and fracture, Philadelphia (PA): ASTM. 3: 243-266.

24. Becht G, Gillespie J W. (1988). Design and analysis of the Cracked Rail Shear specimen for Mode III interlaminar fracture. Composite Science and Technology. 31: 143-157.

25. Lee S M. (1993). An Edge Crack Torsion Method for Mode III Delamination Fracture Testing. Journal of Composite Technology and Research. 15(3): 193-201.

26. Choi N S, Kinloch A J, Williams J G. (1999). Delamination fracture of multidirectional carbon-fiber /epoxy composites under Mode I, Mode II and Mixed-Mode I/II loading. Journal of Composite Material. 33: 73-100.

27. Andersons J, Konig M. (2004). Dependence of fracture toughness of composite laminates on interface ply orientations and delamination growth direction. Composite Science and Technology. 64: 2139-2152. 
28. A B de Morais, A.B. Pereira. (2006). Mixed mode I + II interlaminar fracture of glass/epoxy multidirectional laminates - Part 1: Analysis. Composites Science and Technology. 66: 1889-1895.

29. F Dharmawan, G Simpson, I Herszberg, S John. (2006). Mixed Mode fracture toughness of GFRP composites. Composite Structures. 75: 328-338.

30. ASTM D6671/ D6671M. (2006). Standard test method for Mixed ModeI - Mode II interlaminar fracture toughness of unidirectional fiber-reinforced polymer-matrix composites.

31. Amar C Garg. (1986). Intralaminar and interlaminar fracture in Graphite /Epoxy laminates. Engineering Fracture Mechanics. 23 (4): 719-733.

32. Parhizgar S, Zachary L W, Sun C T. (1982). Application of the principle of linear elastic mechanics to composite materials. International Journal of Fracture. 20: 3-15.

33. S Jose, R Ramesh Kumar, M K Jana, G. Venkateshwara Rao. (2001). Intralaminar fracture toughness of a cross -ply laminate and its constituent sub-laminates. Composite Science and Technology. 61: 1115-1122.

34. Pinho, Robinson P, Lannucci L. (2006). Fracture toughness of the tensile and compressive fiber failure modes in laminated composites. Composite Science and Technology. 66: 120692079

35. Pinho, Robinson P, Lannucci L. (2009). Developing a four point bend specimen to measure the mode I intralaminar fracture toughness of unidirectional laminated composites. Composite Science and Technology. 69:1303-1309.

36. ASTM D5045. (1996). Standard test method for plane strain fracture and strain energy release rate of plastic materials. 